\title{
Biến đổi khí hậu làm gia tăng mực nước biển ở các đại dương
}

Phạm Hà Trang, Đỗ Anh Tuấn, Đỗ Thị Hương Trà, Lê Thị Thanh Truyền, Lê Thu Trang, Nguyễn Minh Trúc, Nguyễn Thị Phương Thảo, Vũ Thị Linh Trang, Cao Thùy Trang, Nguyễn Thị Phương Thảo, Trần Thị Quỳnh Trang.
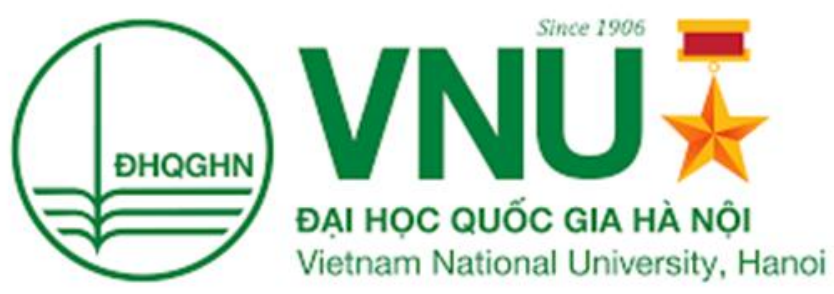

Đại học Quốc Gia Hà Nội

Ngày 03 tháng 01 năm 2022

Preprint DOI: 10.31219/osf.io/ej48w

Biến đổi khí hậu là một thách thức toàn cầu, ảnh hưởng trực tiếp đến hệ sinh thái, tài nguyên môi trường và cuộc sống của con người. Một trong những hệ lụy của nó là vấn đề diện tích mặt biểnvà đại dương, mực nước biển tăng lên từng ngày.

Theo số liệu thống kê của Liên hợp quốc, mực nước biển đại dương trên toàn cầu đã tăng từ $15-20 \mathrm{~cm}$ kể từ năm 1900. Lượng băng mất đi trên toàn cầu tăng từ 760 tỉ tấn mỗi năm trong những năm 1990 lên 1200 tỉ tấn mỗi năm trong những năm 2010, có nghĩa là mức tăng hơn $60 \%$ so với tổng 28000 tỉ tấn băng tan. Đã có 74 sông băng kết thúc chính thức ở vùng biển sâu, hơn một nửa lượng băng mất đi ở Bắc bán cầu (TNO, 2015).

Đến năm 2100, mực nước biển sẽ dâng lên 16 inch, thung lũng Silicon của Mỹ có nguy cơ bị nước biển nhấn chìm, Vellinge thuộc hạt Skane của Thụy Điển sẽ có mực nước biển cao tới $75 \mathrm{~cm}$ và đối diện với tình trạng ngập lụt. Tại Hà Lan, mỗi năm mực nước biển tăng lên $0.2 \mathrm{~cm}$ do tan chảy băng và đại dương đang nóng lên. Đối với Việt Nam, nước biển dâng có thể khiến 40\% diện tích đồng bằng sông Cửu Long sẽ bị nhiễm mặn, thậm chí có nhiều khu vực sẽ bị ngập sâu vĩnh viễn (TNO, 2015). 


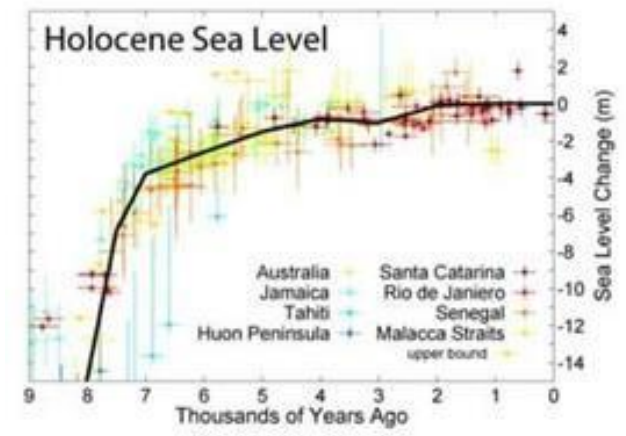

Hinh 1: Nước biến dâng trong khoáng 8000 năm trở lại đây (Nguồn: R.A. Rohde, 2006, Global Warming Art project).

Tình trạng ấm lên toàn cầu xuất phát từ 2 nhóm là nguyên nhân khách quan và nguyên nhân chủ quan. Sự nóng lên toàn cầu bởi khí thải công nghiệp; sử dụng nước ngầm không bền vững, ngăn nước trong hồ nhân tạo, sản xuất công nghiệp, phá rừng, sử dụng các loại khí độc hại là lí do chính khiến lượng khí $\mathrm{CO} 2$ tăng cao. Hơn thế nữa, hiện tượng băng tan làm gia tăng hiện tượng ấm lên toàn cầu. Đây là do băng phản chiếu ánh sáng mặt trời nhiều hơn nước, do đó khi không có những biển băng, đại dương sẽ hấp thụ nhiều nhiệt hơn và trở nên ấm hơn. Thêm vào đó, khi nhiệt độ trái đất ấm dần lên, nước biển sẽ giãn nở theo nhiệt độ khiến mực nước ngày một dângcao.
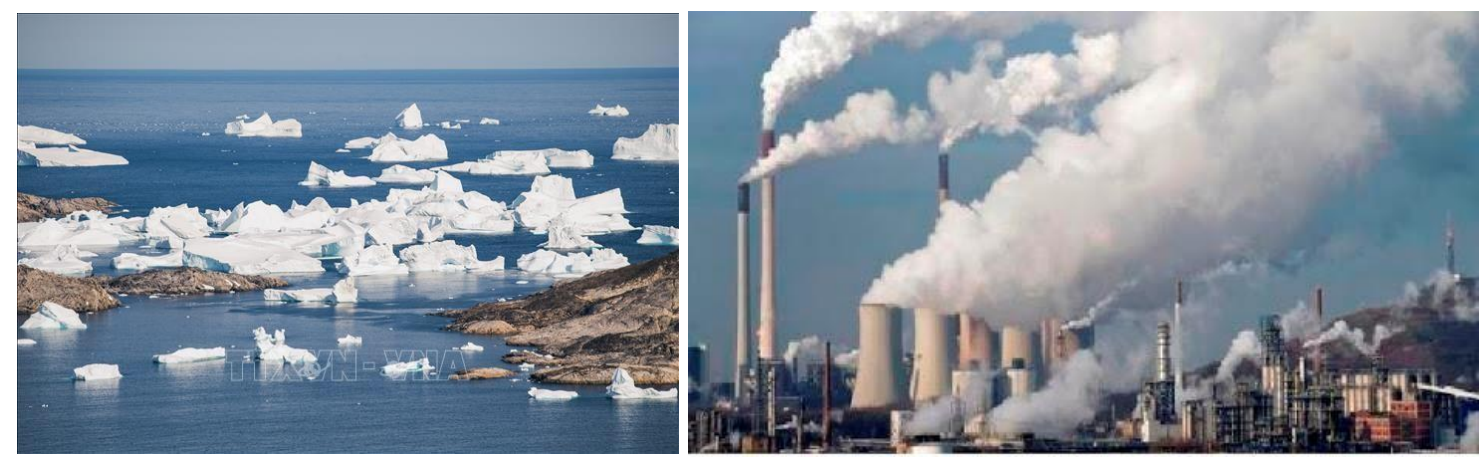

Hình 2. Thực trạng băng tan và khí thải công nghiệp dẫn đến sự nóng lên toàn cầu.

Nguồn: AFP/TTXVN

Sự biến đổi do tác động của khí hậu đối với dự trữ nước trong đất và tình trạng mất nước từ các lòng chảo gây nên sự chuyển giao cơ cấu, sự thay đổi trong hoạt động mặt trời và quỹ đạo trái đất, những trận động đất cường độ lớn làm biến dạng vỏ Trái Đất, tỉ lệ nước mặn nước ngọt trên Trái Đất, ...

Tình trạng Trái Đất ấm lên được xác định là nguyên nhân chính làm tan chảy các dòng sông băng, do đó khiến mực nước biển ngày càng dâng cao...(Hà Anh, 2021; Nguyễn Luận, 2019; Phương, 2019).

Việc diện tích mặt biển và mực nước biển tăng nhanh dẫn đến nhiều tổn thất nặng nề về mọi mặt:

- Môi trường: Số lượng các hiện tượng tự nhiên cực đoan như: mưa lớn, giông tố, lũ lụt, hạn hán, cháy rừng, lốc xoáy, các đợt nắng nóng hoặc rét đậm rét hại ngày càng gia tăng; quần thể các loài động thực vật đặc dụng và quý hiếm ngày càng suy kiệt và có nguy cơ tuyệt chủng;... 


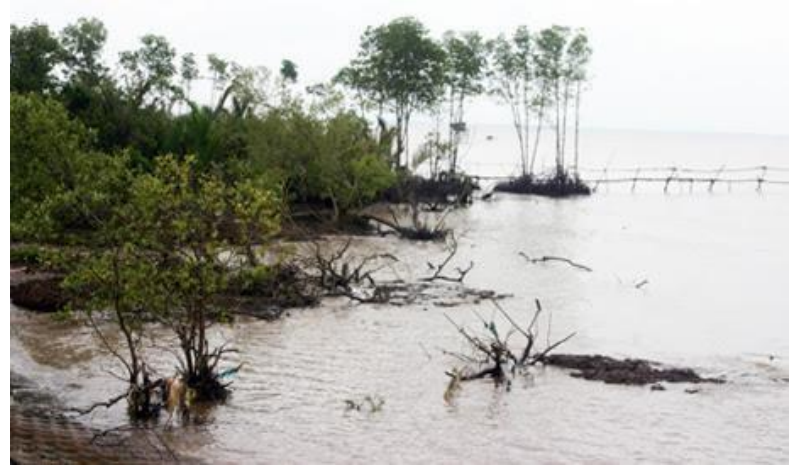

Hình 3. Hậu quả của nước biển dâng. Nguồn: Internet

- Kinh tế: Giảm mức tăng trưởng kinh tế của nhiều quốc gia. Đến năm 2030, nền kinh tế toàn cầu có thể mất 2000 tỉ USD do biến đổi khí hậu. Theo Số liệu của tổ chức Phi chính chủ Oxfam Anh thì các nền kinh tế đang phát triển có thể bị thiệt hại 1700 tỉ USD/năm vào năm 2050 (CTV Lê Ngọc, 2021).

- Xã hội: Tình trạng xâm nhập mặn ở khu vực ven biển làm thu hẹp diện tích đất nông nghiệp và diện tích mặt biển tăng ảnh hưởng lớn đến cấu trúc lao động trong xã hội (Nguyễn Thị Lan, 2019).

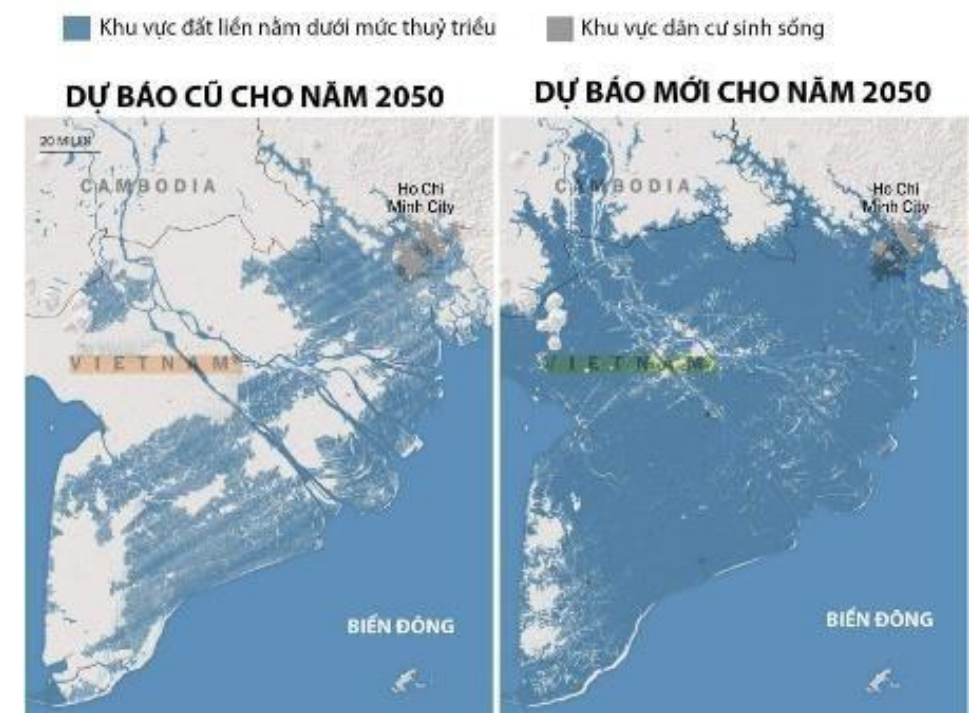

Hình 4. Mực nước biển dụ đoán trong tương lai ở miền Nam nước ta. Nguồn: New York Times

Tại hội nghị về Biến đổi khí hậu của Liên Hợp Quốc 2015, Paris đã đưa ra Công ước khung của Liên Hợp Quốc về biến đổi khí hậu (UNFCCC) nhằm xây dựng và thực thi các biện pháp trong mục tiêu giảm thiểu sự nóng lên toàn cầu (Sara Phillips, 2015). Để đạt mục tiêu duy trì mức tăng nhiệt độ là $1.5^{\circ} \mathrm{C}$, Hội nghị COP26 tại Glasgow diễn ra ngày 1/11/2021 đã đưa ra ba cách thức có thể đẩy nhanh tiến độ, đó là: thực hiện các kế hoạch đề ra đúng hạn; điều chỉnh các thỏa thuận 
tài chính và tăng cường hơn nữa sự phối hợp đa phương. Theo đó, 197 quốc gia tham gia đã đồng ý kí thỏa thuận mới được gọi là Hiệp ước Khí hậu Glasgow; Hơn 140 quốc gia cam kết đạt mức phát thải ròng bằng không. Các quốc gia trong nhóm này chiếm $90 \% \mathrm{GDP}$ toàn cầu; Hơn 100 quốc gia, trong đó có Brasil đã cam kết đẩy lùi nạn phá rừng vào năm 2030; Hơn 40 quốc gia cam kết loại bỏ khai thác than đá; Ấn Độ hứa sẽ rút một nửa nhu cầu năng lượng từ các nguồn tái tạo vào năm 2030 (Xuân Phong, 2021).

Website chính thức của Liên hợp quốc đã liệt kê 7 nỗ lực, hành động nổi bật liên quan đến cuộc chiến chống biến đổi khí hậu trước thềm Hội nghị về Công ước khung của Liên hợp quốc về biến đổi khí hậu lần thứ 26 (COP26) diễn ra tháng 11 tại Glasgow, Anh.

Thứ nhất, đầu tư mạnh tay cho năng lượng sạch: Các chính phủ cùng khu vực tư nhân đã cam kết đầu tư 400 tỉ USD cho năng lượng sạch tại Đối thoại cấp cao về Năng lượng của Liên hợp quốc tháng 9 vừa qua, 35 quốc gia, từ các đảo quốc nhỏ bé cho tới các cường quốc đang nổi, các nền kinh tế phát triển đều đưa ra cam kết quan trọng về nguồn năng lượng mới dưới hình thức "Khế ước năng lượng". Nổi bật trong số này là thỏa thuận về không cấp phép xây dựng mới các nhà máy nhiệt điện với sự tham gia của Sri Lanka, Chile, Đan Mạch, Pháp, Đức, Anh và Montenegro.

Thứ hai, Mỹ, Trung Quốc hành động chống biến đổi khí hậu: Trong tuần lễ cấp cao kỳ họp Đại hội đồng Liên hợp quốc lần thứ 76 cuối tháng 9 vừa qua, hai nền kinh tế lớn nhất thế giới đều đưa ra cam kết tham vọng hơn trong hành động chống biến đổi khí hậu. Tổng thống Joe Biden thông báo Mỹ sẽ tăng đáng kể đóng góp tài chính cho nỗ lực quốc tế trên lĩnh vực này, với số tiền vào khoảng 11,4 tỉ USD/năm. Cùng lúc, Chủ tịch Tập Cận Bình cam kết Trung Quốc sẽ chấm dứt việc viện trợ, cấp vốn xây dựng các nhà máy nhiệt điện ở nước ngoài, thay vào Bắc Kinh sẽ ủng hộ, hậu thuẫn các nhà máy năng lượng xanh, nhà máy phát điện ít thải ra carbon.

Thứ ba, tuần lễ khí hậu châu Phi tạo cú hích cho hành động khu vực: Cuối tháng 9, đại diện các quốc gia châu Phi đã có phiên họp trực tuyến trong khuôn khổ Tuần lễ khí hậu châu phi 2021 (ACW 2021), nhằm nêu bật những hành động chống biến đổi khí hậu, tìm kiếm khả năng hợp tác và đưa ra nhiều giải pháp tham vọng . Hơn 1.600 đại biểu đã tham gia cuộc gặp lần này dưới sự chủ trì của nước chủ nhà Uganda. Sự kiện quy tụ đại diện cho các chính phủ ở tất cả các cấp cùng với giới lãnh đạo khu vực tư nhân, chuyên gia, học giả. Ông Janet Rogan, Đại sứ khu vực cho Trung Đông châu Phi tại COP26 cho biết cuộc thảo luận này giúp các bên liên quan xây dựng quan hệ đối tác mới, củng cố các nền tảng hợp tác đã có.

Thứ tư, Nước chủ nhà COP26 "nhắc nhở” các nước đóng góp tài chính: Ngay trước phiên họp của Đại hội đồng Liên hợp quốc khóa 76, ông Borris Johnson, Thủ tướng Anh - nước chủ nhà COP26, đã triệu tập một phiên họp khẩn để thúc ép các bên hành động nhiều hơn nữa trong chitiêu tài chính chống biến đổi khí hậu. 
Thứ năm, cải cách hệ thống lương thực toàn cầu: Hệ thống sản xuất lương thực gây ra $1 / 3$ tổng phát thải khí nhà kính, tiêu tốn tới $70 \%$ dữ trữ nước ngọt và chiếm $80 \%$ nguyên nhân gây ra tổn thất đa dạng sinh học. Hệ thống sản xuất bền vững vì thế được coi là giải pháp quan trọng giúp xử lý những thách thức này.Ngày 23/9, Liên hợp quốc đã tổ chức Hội nghị thượng đỉnh hệ thống lương thực toàn cầu trong khuôn khổ kỳ họp khóa 76 Đại hội đồng. Tại đây, các nhà lãnh đạo thế giới cùng lên tiếng kêu gọi hành động tầm quốc gia, khu vực để dịch chuyển cách thức sản xuất, tiêu thụ và thải bỏ lương thực. Tại hội nghị, nhiều nước đã thông báo về những sáng kiến mới, hướng đến mục tiêu bảo đảm nhu cầu dinh dưỡng cho dân số bằng hệ thống sản xuất lươngthực gắn với chống biến đổi khí hậu, bảo vệ đa dạng sinh học, sinh kế của người dân.

Thứ sáu, giới trẻ hành động chống biến đổi khí hậu: Hơn 400 nhà hoạt động trong độ tuổi từ 15-29 đến từ 186 nước đã tham gia cuộc gặp "Thế hệ trẻ hành động chống biến đổi khí hậu" (Youth4Climate), diễn ra từ 28-30/9 tại Milan, Italy. Đây là dịp để giới trẻ hối thúc thế giới cùng hành động nhiều hơn nữa trong cuộc chiến này. Từ đó vấn đề nghiên cứu, khoa học, đào tạo, giáo dục thế hệ trẻ văn hóa nhận thức và hành động vì môi trường là rất quan trọng (Nguyen \& Vuong, 2021; Q. Vuong, 2020).

Thứ bảy, Hội nghị tiền COP26: Trước mỗi một kỳ COP sẽ có một cuộc gặp trù bị, được tổ chức trước đó khoảng một tháng, gọi là Hội nghị tiền COP. Hội nghị năm nay diễn ra tại Milan, Italy,từ 30/9-2/10.(Báo tin tức - TTXVN, 2021)

Nhiệt độ trái đất trong tương lai có tăng hay không phụ thuộc phần lớn vào cách hành xử và lối sống của mỗi con người. Chúng ta liệu vẫn tiếp tục chặt phá rừng, xả thải khí $\mathrm{CO} 2$, tiêu thụ nhiều nhiên liệu đốt,các sản phẩm công nghiệp hay chúng ta sẽ đổi phát triển năng lượng sạch, sống xanh và bền vững hơn?. Chưa kể, chúng ta cũng chưa hoàn toàn hiểu hết về hệ thống khí hậu và đại dương của Trái đất. Nước biển dâng sẽ gắn liền với sự ấm lên toàn cầu. Trong kịch bản "lạc quan" nhất ,lượng nước biển cũng dâng lên $35 \mathrm{~cm}$. Theo kịch bản "xấu" nhất, nước biển trên Trái Đất sẽ dâng lên $86 \mathrm{~cm}$ so với này nay. Điều đó cho thấy, nhiều khả năng chúng ta sẽ đối diện với nguy cơ nước biển tăng từ $50 \mathrm{~cm}$ trở lên, lượng tăng hơn gấp đôi so với một thể kỷ trước. Kể cả khi chúng ta chấm dứt hoàn toàn việc thải vào khí quyển khí nhà kính, thì không chỉ nhiệt độ toàn cầu mà cả mực nước biển về dài hạn vẫn tiếp tục tăng chứ không giảm đi.

Trong dài hạn, mực nước biển trung bình toàn cầu vẫn sẽ liên tực thay đổi. Sự ra đời của các cuộc cách mạng công nghiệp đã khiến cho Trái Đất ngày càng ấm dần lên, kéo theo đó là nhiều nguyên nhân khác nhau dẫn dến sự gia tăng nhanh chóng của mực nước biển toàn cầu: băng tan, giãn nở của nước và các thay đổi trong hệ thống khí hậu Trái đất,gây thiệt hại cho kinh tế toàn cầu hàng ngàn tỉ USD với nhiều hệ lụy phát triển.

Tóm lại, tìm cách thích ứng một cách hiệu quả với biến đổi khí hậu là một trong những bài toán khó nhất mà loài người chúng ta cần hợp tác phải quyết trong thế kỷ này (Khuc, 2022; Q.-H. Vuong, 2021). Xây dựng văn hóa môi trường cùng với sự tham gia của doanh nghiệp (doanh 
nhân), sử dụng cơ chế sáng tạo 3D (Napier \& Vuong, 2013; Q. H. Vuong, 2021; Q. H. Vuong \& Napier, 2014) sẽ là chìa khóa cho vấn đề môi trường này. Mặc dù, toàn thế giới đã nâng cao nhận thức về hậu quả của biến đổi khí hậu và đưa ra các biện pháp cụ thể với sự cam kết và ràng buộc cả về kinh tế và pháp luật, nhưng điều đó không thể khẳng định tương lai tương sáng của nhân loại trong cuộc chiến chống biến đổi khí hậu. Nếu như không có sự chung tay góp sức và hành động nghiêm túc của những cường quốc hàng đầu trên thế giới - những nhà vô địch về lượng khí thải phát ra, thì việc hủy hoại môi trường và khí hậu sẽ diễn tiến lâu dài và để lại những hậu quả nghiêm trọng.

\section{Tài liệu tham khảo}

Báo tin tức - TTXVN. (2021). 7 nỗ lực chống biến đổi khí hậu nổi bật trước thềm Hội nghị COP26. Bộ Công Thuơng Việt Nam. https://moit.gov.vn/bao-ve-moi-truong/7-no-lucchong-bien-doi-khi-hau-noi-bat-truoc-them-hoi-nghi-cop26.html

CTV Lê Ngọc. (2021). Những thay đổi đáng lưu ý của tự nhiên gần đây. Ngayday. https://ngayday.com/nhung-thay-doi-dang-luu-y-cua-tu-nhien-gan-day

Hà Anh. (2021). Tìm ra nguyên nhân gây mực nước biển trên toàn cầu dâng cao. Súc Khỏe Đời Sống. https://suckhoedoisong.vn/tim-ra-nguyen-nhan-gay-muc-nuoc-bien-tren-toan-caudang-cao-169189336.htm

Khuc, Q. Van. (2022). Về khả năng ứng dụng của hệ xử lý thông tin 3D và nguyên lý bán dẫn giá trị trong tìm kiếm giải pháp cho vấn đề ô nhiễm môi trường và biến đổi khí hậu ở Việt Nam. Tạp Chí Kinh Tế và Dư Báo, 1, 1-5. https://kinhtevadubao.vn/ve-kha-nang-ung-dungcua-he-xu-ly-thong-tin-3d-va-nguyen-ly-ban-dan-gia-tri-trong-tim-kiem-giai-phap-cho-vande-o-nhiem-moi-truong-va-bien-doi-khi-hau-o-viet-nam-20840.html

Napier, N. K., \& Vuong, Q. H. (2013). Serendipity as a strategic advantage?. In: Wilkinson (ed.) Strategic Management in the 21st Century (pp. 175-199). Praeger/ABC-Clio. International Journal of Industrial Organization, 19(3-4), 543-566. https://doi.org/10.1016/S01677187(99)00018-1

Nguyễn Luận. (2019). Nước biển dâng - Hệ lụy của biến đổi khí hậu. Kinh Tế Môi Truờng. https://kinhtemoitruong.vn/nuoc-bien-dang-he-luy-cua-bien-doi-khi-hau-9625.html

Nguyen, M.-H., \& Vuong, Q.-H. (2021). Evaluation of the Aichi Biodiversity Targets: the international collaboration trilemma in interdisciplinary research. Pacific Conservation Biology. https://doi.org/10.1071/pc21026

Nguyễn Thị Lan. (2019). Nghiên cứu ảnh hưởng của biến đổi khí hậu tới kinh tế nông nghiệp Việt Nam. Tạp Chí Tài Chính.

Phương, L. (2019). Phát hiện mới về nguyên nhân hàng đầu khiến mực nước biển dâng cao. Bảo vẹ Môi Truờng. https://www.vietnamplus.vn/phat-hien-moi-ve-nguyen-nhan-hang-daukhien-muc-nuoc-bien-dang-cao/572792.vnp

Sara Phillips. (2015). NParis climate deal: Historic climate change agreement reached at 
COP21o Title. $A B C$ NEWS. https://www.abc.net.au/news/2015-12-12/world-adoptsclimate-deal-at-paris-talks/7023712?nw=0\&r=Gallery

TNO. (2015). Vì sao nước biển dâng cao? Điện Tử Tiêu Dùng. https://dientutieudung.vn/cafe/i12335-vi-sao-nuoc-bien-dang-cao

Vuong, Q.-H. (2021). Western monopoly of climate science is creating an eco-deficit culture. Economy, Land \& Climate Insight, 11, 1-9. https://elc-insight.org/western-monopoly-ofclimat

Vuong, Q. (2020). From children's s literature to sustainability science, and young scientists for a more sustainable Earth From children's literature to sustainability science, and young scientists for a more sustainable Earth. Journal of Sustainability Education, 24(December), 2019-2021.

Vuong, Q. H. (2021). The semiconducting principle of monetary and environmental values exchange. Economics and Business Letters, 10(3), 284-290.

https://doi.org/10.17811/ebl.10.3.2021.284-290

Vuong, Q. H., \& Napier, N. K. (2014). Making creativity: the value of multiple filters in the innovation process. International Journal of Transitions and Innovation Systems, 3(4), 294. https://doi.org/10.1504/ijtis.2014.068306

Xuân Phong. (2021). Cơ hội cuối cùng để cứu hành tinh? Quân Đội Nhân Dân. https://www.qdnd.vn/quoc-te/binh-luan/co-hoi-cuoi-cung-de-cuu-hanh-tinh-675108 